
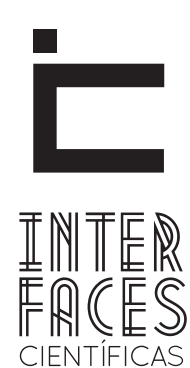

EDUCAÇÃO

ISSN IMPRESSO 2316-333X

E-ISSN 2316-3828

DOI-10.17564/2316-3828.2017v5n3p97-112

\title{
SOBRE O TEMPO E O CONTROLE DOS CORPOS NA ESCOLA PRIMÁRIA: 0 QUE DIZEM DEZESSETE PROFESSORES DO TERRITÓRIO DA GRANDE ARACAJU [1930 -1961]
}

\author{
ON TIME AND CONTROL OF BODIES IN PRIMARY SCHOOL: WHAT THEY SAY THE TERRITORY \\ OF SEVENTEEN TEACHERS GREAT ARACAJU [1930 - 1961] \\ EL TIEMPO Y EL CONTROL DE LOS CUERPOS EN LA ESCUELA PRIMARIA: LO QUE DICEN DIECISIETE MAESTROS \\ DEL TERRITÓRIO DE ARACAJU [1930 - 1961].
}

Rony Rei do Nascimento Silva ${ }^{1}$

\section{RESUMO}

O presente artigo objetiva compreender como se estabeleceram os ritos e rotinas do tempo escolar, na Escola Primária no território da Grande Aracaju, no período que compreende 1930-1961. De tal maneira, tomamos enquanto objeto de estudo os relatos orais de 17 professores(as) aposentados. Partimos dos pressupostos da História Cultural Francesa, segundo as análises de Roger Chartier (1990) e, nessa mesma direção operamos com a pesquisa bibliográfica e a metodologia da
História Oral. Assim, conjecturamos que os ritos e rotinas é o resultado das determinações legais, institucionais e a atuação de sujeitos que vivenciaram e também instituíram tempos e controles na escola.

\section{PALAVRAS-CHAVE}

Escola Primária. Ritos.Tempo. Grande Aracaju. 


\section{ABSTRACT}

Abstract: this paper aims to understand how settled the rituals and routines of school time in primary school within the Great Aracaju, in the period comprising 1930 to 1961 . So, we take as an object of study, the oral histories of 17 teachers (as) retired. We set out the assumptions of the French Cultural History, according to the analyzes Roger Chartier (1990) and operate in the same direction with the literature and methodology of oral history. Thus, we conjecture that the rituals and routines is the result of legal, institutional determinations and performance of subjects who experienced and well established times and controls the school.

\section{KEYWORDS}

Primary School. Rites. Time. Great Aracaju.

\section{RESUMEN}

Este artículo tiene como objetivo comprender cómo se establecieron los rituales y rutinas de tiempo escolar, en la escuela primaria en el territorio de la Grande Aracaju, en el periodo que comprende desde 1930 hasta 1961. Por lo tanto, se toma como objeto de estudio los informes orales de 17 maestros (as) retirados. Empezamos por los presupuestos de la Historia Cultural Francesa, de acuerdo con los análisis de Roger Chartier (1990) y operamos, en la misma dirección, con la literatura y la metodología de la historia oral. Así, se vislumbra que los rituales y rutinas es el resultado de los requisitos legales, institucionales y de rendimiento de los sujetos que experimentaron y también establecieron los tiempos y los controles en la escuela.

\section{PALABRAS-CLAVE}

Escuela primaria. Rituales. Tiempo. Gran Aracaju. 


\section{INTRODUÇÃo DO SCRIPT}

Quando eu era criança, fazia a escola das minhas bonecas... Eu pegava o papel do pão, para fazer um caderninho. Fazia as carteirinhas da escola com caixa de fósforos. Fiz farda com a blusa branca, gola de marinheiro e saia azul. [...] Elas eram minhas alunas, eu não sabia escrever, mesmo assim fazia as letras de garrancho. Lurdes Tavares dos Santos (2013).

Tomamos emprestado de Lurdes Tavares dos Santos a cena escolar evocada pelas suas lembranças de menina. No palco das suas imaginações e brincadeiras, pequenas bonecas encenavam a vida cotidiana da escola, entre cadernos, carteiras, uniformes, rabiscos... Essa "escola das bonecas" chegou aos nossos olhos e ouvidos pela tela da memória de uma dos(as) dezessete professores(as) aposentados(as), entrevistados(as) para a composição desta pesquisa. Foi através dela e de suas "colegas" que sentamos e assistimos cenas de vidas, que hora se apresentavam em preto e branco, ora em multiplicidades de cores.

0 longa-metragem da vida passada é narrado pelas suas vozes cansadas e trêmulas, que ainda assim, faz sobressair cores, formas, cheiros, sabores, figurinos, aprendizados... 0 "filme ${ }^{1}$ editado" foi resultado do projeto de pesquisa "Modos de Educar: Práticas escolares e cultura escolar no território da Grande Aracaju"", que teve por objeto de estudo os relatos orais dos educado-

\footnotetext{
1 A alegoria é pensada neste texto para representar uma narrativa histórica a ser construída a partir de fragmentos, fazendo a analogia com as memórias de nossas personagens - como as cenas que compõem um filme, essas memórias constituem uma história que muito revela sobre a história da educação em Sergipe.

20 projeto de pesquisa “Modos de Educar: Práticas escolares e cultura escolar no território da Grande Aracaju", deriva do projeto "guarda-chuva" "Memória Oral da Educação Sergipana”. O projeto está dividido de acordo com os territórios sergipanos perfazendo um total de oito sub-projetos. 0 objetivo é compreender como se constituíram os modos de educar de educadores atuantes no território sergipano; para tanto está sendo necessário: mapear os educadores mais antigos e de maior representatividade na área educacional; identificar as práticas escolares, próprias do tempo e do espaço escolar e analisar a cultura de escola que fora produzida nas instituições educativas do território sergipano. 0 propósito é possibilitar a produção de saberes e entendimentos acerca dos modos de educar e dos métodos de ensino, fomentando interações e trocas no âmbito da pesquisa e do conhecimento, envolvendo Instituições de Ensino, grupos de pesquisas, discentes e docentes e pesquisadores relacionados a áreas afins. Projeto financiado pelo CNPq. Edital MCTI/CNPq/MEC/CAPES. N. 18/2012. No do processo 405366/2012-4. Bolsas de Iniciação científica CNPq e PROBIC/UNIT.
}

res do referido território. Dentro dessa motivação, colecionamos dezessete entrevistas com professores(as), com idade entre 69 e 91 anos, que compõe o acervo digital "Memória Oral da Educação Sergipana".

0 referido acervo de entrevistas reúne trajetórias de vidas plurais. Dos dezessete entrevistados(as) há uma professora que cursou apenas o Primário, nove cursaram o Ginasial, quatro cursaram o Normal e três o Superior. Vale ressaltar que dois tornaram-se bacharéis em Direitos, um membro Academia Sergipana de Letras e uma vereadora. Chegamos até eles(as) por intermédio dos arquivos e registros armazenados nas Diretorias Regionais de Educação (DR) e Secretarias Municipais de Educação (SME), localizados nos nove municípios que compõe território, a saber: Aracaju, Barra dos Coqueiros, Itaporanga D’Ajuda, Laranjeiras, Maruim, Riachuelo, Nossa Senhora do Socorro, Santo Amaro das Brotas e São Cristóvão.

Desse modo, o presente artigo, tal qual um longametragem, pretende revelar os resultados do projeto de pesquisa realizado entre agosto de 2012 a julho de 2013. O nosso objetivo foi, em um primeiro momento, compreender como se estabeleceram os ritos e rotinas do tempo escolar, para tanto partimos da análise dos exames, recreios e comemorações patrióticas que primavam por significar a temporalidade escolar. A luz do referencial teórico da História Cultural o nosso olhar esteve voltado, no segundo momento no texto, para o controle dos corpos pelos uniformes escolares, inspeções, castigos físicos e práticas religiosas.

Para alcançar tais objetivos seguimos algumas etapas, a saber: inicialmente mapeamos e entrevistamos os educadores mais idosos e, em seguida identificamos por meio da transcrição e análise das entrevistas as práticas escolares próprias do tempo e espaço escolar. 0 período estudado corresponde a um recorte que compreende o início das edições da revista "Escola Nova" que nos anos de 1930 e 1931 dedicava-se à divulgação da pedagogia moderna, até a primeira versão da Lei de Diretrizes e Bases da Educação Nacional - LDB (Lei nº 4.024/61), promulgada em 1961.

Antes de trazer à tona esse filme do passado/páginas da História da Educação em Sergipe, convidamos 
para entrar em cena os 17 atores/professores(as), que ora sentados em suas cadeiras de balanço, ora em seus cômodos assentos, preparam seu próprio cenário cenográfico, a fim de dar a ver suas histórias, que vão do particular ao geral e que por isso contribuem para o entendimento de uma página da História da Educação qual queremos dar a ver.

Nos bastidores dessa gravação levantamos a hipótese de que o os ritos e rotinas, encontrados na escola primária no território da Grande Aracaju, é fruto das combinações estabelecidas entre as determinações normativas e as práticas dos sujeitos envolvidos no cotidiano escolar. Para confirmar ou refutar tal hipótese, interrogamos: Como se constituíram os ritos e rotinas do tempo escolar na escola primária no território da Grande Aracaju? Quais lógicas e significados circunscreviam o controle dos corpos?

\section{ROTEIRO: AS EDIÇÕES TEÓRICAS E METODOLÓGICAS}

A apropriação do objeto de estudo do aqui instituído, só foi possível com o auxílio da História Cultural Francesa - campo historiográfico que despontou nas últimas décadas do século $X X$, porém com claros antecedentes desde o início do mesmo século - é um campo de pesquisa que nos oferece diferentes possibilidades de fontes, objetos e tratamentos analíticos e metodológicos. Segundo Chartier (1990), a História Cultural assume importante papel em decifrar o modo como em diferentes lugares e épocas “uma realidade social é construída, pensada, dada a ler." De tal maneira, esse campo voltou-se para temáticas atravessados pela polissêmica noção de "cultura" e, de modo mais amplo para a vida representada socialmente.

Assim, a História Cultural permite a análise dos processos com os quais se constroem lógicas e sentidos, uma vez que uma das suas principais lógicas, as representações podem ser entendidas como "[...] esquemas intelectuais, que criam as figuras graças às quais o presente pode adquirir sentido, o outro tornar-se inteligível e o espaço ser decifrado" (CHARTIER, 1990, p. 17). Sabemos que a História Cultural não se trata de um campo uniforme, uma vez que existiram múltiplas gerações de historiadores com tendências e perspectivas diversificadas, evidência disto é a diversidade de temas, objetos e fontes apropriados ao longo de sua trajetória historiográfica. Contudo, foi pelas aberturas feitas pela História Cultural, que foi possível agregar as fontes orais em uma investigação acerca da História Oral.

Foi pelo posicionamento da nossa câmara que podemos captar multiplicidades de narrativas, por entre: registros, cortes, filmagens e censuras. Tais entrevistas foram concedidas ${ }^{3}$ nas residências dos entrevistados, distribuídos pelos nove municípios que integram o território da Grande Aracaju. Para tanto, lançamos mão de roteiros semiestruturados, seguindo o modelo do geral, específico e parcial de acordo com o "Manual de História Oral” de Alberti (2004) e, conforme suas instruções decidimos pela realização das entrevistas de história de vida.

Segundo Alberti (2004) tais modalidades de entrevistas “[...] tem como centro de interesse o próprio indivíduo na história, incluindo sua trajetória desde a infância até o momento em que fala, passando pelos diversos acontecimentos e conjunturas que presenciou, vivenciou ou de que se inteirou" (ALBERTI, 2004, p. 38). Para adentramos pelos meandros das trajetórias dos professores(as), buscamos nos conceitos de "cultura escolar" de Julia (2001) e "Práticas Escolares" de Faria Filho e Vidal (2000) o modo de ler e dar a ver suas memórias escolares.

\footnotetext{
3 As entrevistas foram cedidas pelos professores, a partir da Carta de Cessão de direitos, dispondo sobre os direitos e deveres do entrevistado, bem como o esclarecimento, sobre uso das entrevistas para fins de pesquisa acadêmica. As entrevistas foram gravadas em áudio e vídeo, sua duração soma o montante de mais de $40 \mathrm{~h} / \mathrm{s}$ e foram devidamente transcritos em Microsoft Word 2010. Estas se encontram armazenadas no acervo, que constituirá o “Centro de Memória da Educação Sergipana” e que serão somadas as outras entrevistas decorrentes dos demais subprojetos. Vale ressaltar, que o projeto "guarda-chuva" "Memória oral da Educação Sergipana" se subdivide conforme os territórios do Estado de Sergipe.
} 


\section{CULTURA ESCOLAR: OS RITOS, ROTINASE 0 TEMPO FRACIONADO ENTRE EXAMES, RECREIOS E COMEMORAÇ̃̃ES PATRIÓTICAS}

O historiador francês Dominique Julia teve dentre suas investigações, uma dedicação aos aspectos que compõe a cultura escolar. Tal trabalho é circunscrito ao período moderno e contemporâneo, mais especificamente entre os séculos XVI e XIX. Seu estudo se destacou por conceber a cultura escolar enquanto objeto histórico. Desse modo, o autor interessou-se pelas normas, pelas finalidades e práticas que conduzem o cotidiano escolar. Para tanto, sua investigação se preocupou em avaliar o papel desempenhado pela profissionalização do trabalho do educador, bem como, pela análise dos conteúdos ensinados e das práticas escolares.

Assim, o pesquisador que se propõe entender a cultura escolar deve considerar que: "[...] a cultura escolar não pode ser estudada sem o exame preciso das relações conflituosas ou pacíficas que ela mantém, a cada período de sua história, com o conjunto das culturas que the são contemporâneas" (JULIA, 2001, p. 35). Desse modo, a cultura escolar, se dá, a partir das trocas culturais ligadas ao tempo e espaço histórico, uma vez que esta guarda em si um conjunto de especificidades que a diferem de outras culturas. Pois, diferentemente da instituição familiar, a escola produz relações cotidianas em seu interior baseadas em normas e práticas eleitas historicamente. Assim,

[...] por cultura escolar é conveniente compreender também, quando isso é possível, as culturas infantis (no sentido antropológico do termo), que se desenvolvem nos pátios de recreio e o afastamento que apresentam em relação às culturas familiares. (JULIA, 2001, p. 11).

As palavras acima, nos convidam a fazer uma reflexão sobre as rotinas estabelecidas entre pátios e recreios escolares. Desse modo, espaços e tempos fazem parte da ordem social e escolar, uma vez que os ritos estabelecidos em muito podem revelar sobre a composição da cultura escolar. Para melhor esclarecer tais processos, tomamos de empréstimo as palavras de Diana Vidal e Luciano Mendes (2000), pois estes entendem que cada escola possui multiplicidades culturais produzidas pelos indivíduos que partiIham do seu cotidiano. Assim, asseverou Diana Vidal e Luciano Mendes (2000): "O tempo e espaço escolar delimita-se, controla-se e materializa-se em quadros de anos/séries, horários, relógios, campainhas, ou em salas específicas, pátios, carteiras individuais ou duplas" (VIDAL; FARIA FILHO, 2000, p. 21).

Como já anunciado voltaremos o nosso olhar para os ritos e rotinas do tempo escolar. Para melhor entender sobre temporalidade escolar, recorremos às narrativas de Maria Valdomira de Carvalho Santos (2013), 80 anos, que revelaram obre a constante vigilância na Escola Isolada em São Cristóvão:

Na Escola Isolada da professora "Julieta" eu ajudava ela com nove anos, mas a professora sempre com 0 olhar atento. Quando eu estudava no Sindicato ${ }^{4}$ também a professora fazia o mesmo, ela dividia as carteiras e marcava o tempo da lição. Parece que ainda estou ouvindo ela dizer: 'Estou de olho, nada de danação!'. Nós éramos como professoras ajudantes, mas "Julieta" sempre vigiando.

É fundamental salientar, que os tipos de escola primária no território da Grande Aracaju estavam centrados basicamente em Escolas Isoladas e Grupos Escolares, estes últimos eram considerados o modelo ideal, na maioria dos casos localizava-se nas capitais e cidades-polo e, serviam como vitrines das ações do Estado no campo da educação escolar e ocupavam prédios: “[...] estrategicamente criados em pontos de grande visibilidade social, cravando no imaginário uma ideia de escola que não alcançou um conjunto mais geral da população, mas teve força para seduzi-la" (GASPAR DA SILVA, 2006, p. 344).

Por sua vez as Escolas Isoladas, criadas convencionalmente nos perímetros suburbanos dos municípios, seriam suprimidas ou "deslocalizadas" pelos suntuo-

4 Funcionava no Sindicato dos Trabalhadores de São Cristóvão uma escola para os filhos dos trabalhadores da Fábrica de Tecido São Cristóvão. 
sos Grupos Escolares. Assim, é imprescindivel dizer que o controle do tempo não se restringia apenas as Escolas Isoladas, pois no Grupo Escolar “Vigário Barroso", também localizado em São Cristóvão, havia a presença controladora do relógio. Sobre a existência do relógio, narrou Etemízia Ramos Batista Andrade (2013), 82 anos:

Eu comecei a estudar em uma Escola Isolada, mas depois foi para "Vigário" em mil novecentos e trinta e cinco [...] Lá foi diferente, tinha as salas de aulas, tinha a diretória do lado e quatro salas de aulas, para cada ano uma. Em baixo tinha o salão do recreio, onde tinha os banheiros. Tinha as carteiras o birô da professora, quadro negro, mapas de Sergipe e do Brasil... O tempo era diferente da Escola Isolada, lá tinha um relógio enorme na parede, por aquele relógio tudo era feito.

O tempo escolar é por certo um símbolo social, resultado de um longo processo de aprendizagem e, portanto, fruto da construção humana, na medida em que ele é construído pela fragmentação do calendário escolar por meio de datas e horários que contempla exames, recreios e comemorações patrióticas que estabelecem rituais que regulam o cotidiano escolar. Assim, as escolas foram com o passar do tempo, tornando-se o que Foucault (1987) denominou de "máquinas de ensinar", porquanto o espaço escolar estava sobre a mira dos olhares dos seus agentes atentos para os corredores, pátios, salas, recreios, filas... De acordo com as narrativas dos professores que atuaram em algumas escolas primárias do território da Grande Aracaju a organização da atividade ficava a cargo do professor.

Como conta Maria Antônia Lira dos Santos (2011), 85 anos, sobre a temporalidade da Escola Isolada de Laranjeiras, no ano de 1937: "Dona Maricas” ensinava os dois turnos, pela manhã e pela tarde, era a mesma turma. [...] Ela abria a escola oito horas, meio dia todo mundo ia para casa, depois voltávamos duas horas e

\footnotetext{
5 Parafraseando Foucault (1987) a organização do sistema de ensino tornava-se "a máquina de ensinar". Pois, pouco a pouco- mas principalmente depois de 1762- o espaço escolar se desdobra; a classe torna-se homogênea; alinhando as classes de idade umas depois das outras; sucessão de assuntos ensinados [...] umas ideias, que marcam uma hierarquia do saber ou das capacidades.
}

ficava até as cinco. Ela dava um intervalo de quinze minutos para brincar". A forma encontrada pela professora indica a necessidade de uma rotina e releva um modelo de operar o tempo para materializar o trabalho escolar. Outro narrador, o professor Genaro de Almeida Brotas (2013), de 69 anos de idade, rememorou sobre a fragmentação do tempo na mesma Escola Isolada em Laranjeiras:

\begin{abstract}
A Escola Isolada, nós costumávamos chamar de escola de dona "Maricas" mesmo. Era uma escola com um salão enorme, com superlotação porque não tinha divisão. Nós íamos do primeiro ano até o quarto com a mesma professora. Elas [as professoras] eram polivalentes. [...] A professora dividia, por exemplo, de segunda a sábado; ela chamava para o quadro, o primeiro ano ia pro quadro na segunda-feira, o segundo ano, na terça; o terceiro na, quarta e o quarto ano, na quinta-feira. E no sábado ia até o meio dia...
\end{abstract}

Percebe-se, grosso modo, nos testemunhos dos nossos sujeitos entrevistados, um quadro de horários organizado pela professora "Maricas" que de alguma forma determinava o tempo do trabalho e a rotina da sala de aula. Segundo Ávila (2012, p. 190) “Nas Escolas Isoladas havia um controle externo, exercido pelos inspetores e pela própria comunidade, e um controle interno [...] realizado pelo professor e absorvido pelos alunos, características observadas principalmente na década de 1930". Vale ressaltar que a professora "Maricas" operava o tempo com vistas a atender todos os alunos da sua turma multisseriada. Marcados por rituais, o tempo escolar torna-se um elemento constitutivo da cultura escolar.

Segundo Julia (2001), o modelo escolar, com vistas ao controle regulado das atividades, estabelece práticas de aprendizagem a partir de uma programação, como consequências temporais razoáveis. Assim, o tempo dentro da escola também é moldado para educar. Maria José Bezerra Siqueira (2013), 82 anos, narra, sobre a sequência das atividades na Escola Isolada em Riachuelo:

Na escola de dona "Elze Dantas" toda sexta feira tinha sabatina. Na escola tinha uma rotina firme [...] Para começar a aula nós rezávamos o Pai Nosso, a Ave Maria, o Anjo da Guarda... Depois cantávamos o Hino 
Nacional, depois ela [a professora] corrigia os deveres e tomava a lição de cada um. Tinha prova todo fim do mês, agora as provas pesadas eram de novembro para dezembro... Nos recreios a gente lanchava, tinha brincadeiras [...] As merendas, a gente levava de casa, quem podia levava um biscoitinho, quem não podia, levava um pedaço de pão, cocada, pé-de-moleque, laranja, banana, essas coisas...

Também, narrou Lindaura da Cruz Oliveira (2013), 77 anos, sobre a sineta que controlava o tempo na Escola "Doutor José Freire da Costa Pinto", na cidade de Nossa Senhora do Socorro:

\begin{abstract}
As aulas eram de segunda a sábado. Direto. De oito horas da manha as doze. E você tinha que chegar na aula dez minutos antes. Dez para as oito tudo mundo chegava, porque quando tocava a sineta, só entrava quando falasse com a diretora. [...] Bom, o recreio era de quinze minutos. Ela [a professora] observava as nossas brincadeiras, porque para brincar mesmo não tinha quase espaço [...] Todos os dias quando chegávamos cantávamos o Hino Nacional com a bandeira hasteada.
\end{abstract}

Tais evidências não foram apenas encontradas em Escolas Isoladas, mas em Grupos Escolares, pois quando ouvimos a narrativa da professora, Maria Aliete Marinho Andrade, 75 anos, sobre a rotina e os exames do Grupo Escolar “Francisco Leite”, no município de Riachuelo, ficou claro que o tempo também foi fracionado por sabatinas, exames, recreios, entre outros:

No Grupo Escolar "Francisco Leite" eu estudei o primário. Lá o tempo era controlado pela professora [...] Tinha a palmatória para os dias da sabatina, que era sempre na sexta-feira. Quando formávamos no quarto ano tinha aquela festa bonita... Para fazer o Ginásio, antes tinha que fazer o "Exame de Admissão" [...] Comporíamos diariamente um rotina, tinha o horário dos alunos merendar, rezar e estudar. 0 recreio sempre ouve, não é como hoje, que os alunos têm liberdade, lá o horário era marcado.

As narrativas das professoras são reveladoras da repartição dos horários da escola. Nesse período, segundo Ávila (2012) o recreio era entendido enquanto um momento de movimentação para as crianças, destacando a necessidade do/a aluno/a de refazer-se do trabalho sedentário da sala de aula. Outro elemento de repartição do tempo escolar era as provas mensais, que seriam feitas preferencialmente por meio de testes que mesuravam e classificavam a aptidão intelectual dos alunos.

O grande marco era o "Exame de Admissão ao Ginásio”, pois segundo Silva (1969) significaria a fase do processo educativo que corresponde à adolescência que, a partir do ponto de vista pedagógico e curricular, atenderiam a necessidades específicas. 0 "Exame de Admissão ao Ginásio”, vigente entre os anos de 1931 e 1971 complementavam a Reforma Francisco Campos, o Decreto no 19.890, de 18 de abril de 1931, estabelecia: "Art. 18 - 0 candidato à matrícula na $1^{\text {a }}$ série de estabelecimento de ensino secundário prestará exame de admissão na segunda quinzena de fevereiro". A respeito do Exame, rememorou Lurdes Tavares dos Santos (2013):

O tempo de prestar o "Exame de Admissão" era muito esperado... O exame marcava o fim do curso primário no "Vigário Barroso" e a nossa passagem para o Ginásio. Eu fui da segunda turma do Ginásio de São Cristóvão, que fez sessenta anos, eu ganhei a medalha [...] A banca examinadora era feita pelos professores de Aracaju. A prova era oral e escrita... Era tanta coisa que quando não tiveram o que me perguntar, o professor de História me perguntou - ‘o que era banzo?' [...] Quando eu prestei o exame eu já era professora sem cursos altos... Era Português, escrita e oral. Ciências, escrito e oral. Geografia, escrito e oral. História, escrito e oral...

Os calendários dos exames cumpriam a finalidade de delimitar as passagens temporais. 0 que nos revela que as determinações de horários fracionam a rotina escolar, pois por meio das narrativas podemos observar os usos e costumes que incluía a oração/reza no primeiro momento; em seguida, a entoação do hino nacional, e no terceiro momento, a correção dos deveres. Tudo isso evidencia que o tempo escolar está atrelado a um processo de aprendizagem e transformação que se desenvolve nos quatro anos do curso primário. As interações sociais e as regulações, também foram

6 Grupo Escolar Vigário Barroso. 
observadas nas datas comemorativas presentes no calendário escolar que de alguma forma disciplinavam o cotidiano.

Segundo Ávila (2012) as datas cívicas eram intensamente festejadas na década de 1940, com destaque para a Independência do Brasil, que oficialmente ocorreu no dia sete de setembro de 1822. Vale ressaltar que as comemorações cívicas estão diretamente ligadas aos momentos políticos pelos quais passavam o país. Tais datas serviram para enfatizar a necessidade de identificação do povo com o sentimento de patriotismo. Assim, narrou Lindaura da Cruz Oliveira (2013), 77 anos, sobre a interiorização dos valores cívicos nas comemorações de sete de setembro, na cidade de Nossa Senhora do Socorro:

Quanto tinha desfile de sete de setembro eu estudava na Escola "Doutor José Freire da Costa Pinto". Eu adorava participar, todo mundo fardado... Hoje o Hino Nacional ninguém sabe total, é os alinhavos, porque o sete de setembro aqui hasteava a bandeira. No dia da bandeira era obrigação hastear a bandeira na prefeitura [...] as fardas azul e branco...

Outro aspecto que deve ser ressaltado com relação aos festejos cívicos são as poesias alusivas à pátria. Estas se constituem quadros de lembranças pregados na parede da memória da professora Lurdes Tavares dos Santos (2013), pois, quando era menina recitava poesias no coreto de São Cristóvão e agora na condição de velha, rememorou as mesmas, em sua cadeira de balanço:

Eu me criei em cima dos coretos recitando poesias... "Uma saudação à bandeira..." [diz recitando] 'Quatro estrelas de intenso fulgor, estendidas em forma de cruz. Símbolo augusto de paz e amor que proclamam o poder de Jesus. Este insumo ao Cruzeiro do Sul, que por noite de paz e bonança, dai-nos rumo seguro...' Essa é uma, a outra é: [diz recitando] 'setembro traz a primavera e aprazível era do reino do universo... Mais bela e mais viçosa, sul e lindas rosas e dálias do jardim. Grandioso e jovial setembro que nos braços nos lembra da data assim rival, em que o Brasil potente ficou independente do velho Portugal. Em hinos bradamos...' Sei uma porção de pedaços assim, porque meus alunos recitaram muita no sete de setembro aqui em
São Cristóvão. Então as professoras que tinha alunos para recitar levavam lá para o coreto e vinha recitar as poesias [...] No sete de setembro era bonito como a gente hoje não pode ver. Tinha bandinhas, as escolas bem vestidas [levanta-se para buscar um antigo álbum de fotografias].

A narrativa acima nos revela a formidável capacidade que a memória tem de embaralhar-se, pois Lurdes Tavares dos Santos no movimento narrativo revisitou as memórias de aluna e professora. Assim, ao ver os álbuns dos seus alunos, da Escola Estadual "Lourival Batista” em São Cristóvão, onde foi professora, narrou saudosamente os trajes de sete de setembro...

[...] eram de meinha branca, o sapatinho branco, tinha na boca da meinha uma listinha vermelha. Aqui a sainhas eram cor de vinho, as blusinhas creme. [diz olhando para fotografia de um ex-aluno] Olhe esse já está pai de filho. Arrumei eles [os alunos] assim, com a bandeira do Brasil, bandeira de Sergipe, bandeira da Escola. Atrás das bandeiras os menininhos da roupa de cor, atrás desses menininhos o resto da escola entrou. [ler os versos de um cartaz] Tinha um verso bonito: 'Juro pela minha honra...' O menino representado Dom Pedro Primeiro, a menina Princesa Isabel... (Lurdes Tavares dos Santos, 2013).

Sobre o mesmo aspecto e imbuída do mesmo sentimento, professora Maria José de Carvalho Eletério (2013) recordou os rituais que compunham o desfile cívico no Grupo Escolar “Felisbelo Freire”, em 1960 no município de Itaporanga D’Ajuda:

Eu organizava os meninos em filas, nem um deles podia sair. Eu também não gostava de filas tortas, eles [os alunos] não podiam conversar. Era com tambores [...] Tudo com a bandeira nacional... Convocava uma [aluna] com a bandeira, outra segurando de um lado a outro... E ali marchando [narra cantando] - 'Já podeis da pátria filhos. Ver contente a mãe gentil; Já raiou a liberdade no horizonte do Brasil. Já raiou a liberdade...' O hino nacional... As meninas olhem [levanta a mão na altura do peito, na posição de sentido] e os meninos olhem [bate continência]. Está vendo? Todo mundo quando começava o hino nacional... [narra cantando] - 'Ouviram do Ipiranga as margens plácidas de um povo herói do brado retumbante...' [canta com a mão em posição de continência] Ensinava o hino da 
bandeira, [narra cantando] -'Salve lindo pendão da esperança! Salve símbolo augusto da paz! Tua nobre presença à lembrança...' Hoje não faz, ninguém ensina um hino, não...

Pela narrativa da professora podemos vislumbrar um contingente de alunos perfilados e organizados conforme uma disposição militar uniformizada. Nesse caso, é oportuno conjecturar que o desfile cívico permitia que as escolas projetassem para as ruas os seus ritos patrióticos, ao mesmo tempo em que corpos exibiam uma demonstração pública de ordem, seguindo uma lógica política que os perfilava.

Parafraseando Ribeiro e Souza (2012) a distribuição dos corpos escolares, alinhando-os em fila a partir do ato de marchar, marca a incorporação de valores militares na cultura escolar. Assim, o calendário escolar foi ganhando significados pelas datas comemorativas, exames, provas, recreios, campainhas... que fracionavam as rotinas e davam sentidos a hábitos e gestos incorporados diariamente. Desse modo, o tempo dentro da escola servia para disciplinar e regulava os sujeitos envolvidos em seu cotidiano.

\section{CONTROLE DOS CORPOS PELOS UNIFORMES E A SALVAÇÃO DA ALMA PELA FÉ: O EDUCAR PELAS PUNIÇÕES, INSPEÇÕES E ORDENAMENTOS}

\begin{abstract}
A farda da Escola Normal era linda... A saia azul marinho preguilhada, a blusa banca e a gola azul marinho, com uma gravata com o numero da série [...] Tinha que ser passada ferro e limpa, era uma exigência da escola.

Maria Ligia Madureira Pina (2011).
\end{abstract}

Era assim o uniforme adotado pelas Escolas Normais, inclusive pela Escola Normal "Rui Barbosa" da capital de Aracaju na década de 1940, o qual foi eternizado na letra samba-canção "Normalista” de autoria de Benedito Lacerda e David Nasser: "Vestida de azul e Branco..." Assim, as alunas tingiram as calçadas e ruas da cidade de Aracaju, quando desfilavam no vigor da jovialidade com seus livros e cadernos na altura do busto. Os uniformes das normalistas eram cuidadosamente inspecionados pela direção da Escola Normal, que por sua vez pretendia orquestrar os corpos das alunas pela institucionalização do uniforme.

Segundo Ribeiro e Souza (2012) “[...] o uniforme escolar se constitui artefato que disciplina, normatiza condutas e corpos e concorre para homogeneizar o espaço escolar" (RIBEIRO; SOUZA, 2012, p. 207). Tal realidade se torna mais evidente na voz da professora, Maria José da Conceição de Oliveira (2013), 81 anos, que usou o verbo "controlar" para falar do uniforme usado na Escola Normal:

\begin{abstract}
A farda era azul e branco, tinha que estar perfeitamente perfeita, não podia estar amarrotada nem suja, por mais pobre que fossemos. Eu mesmo era muito pobre, mas a minha farda era um brinco [...] A direção da escola controlava os uniformes, tinha um inspetor que nos recebia na porta. Ele [o inspetor] nos olhava de cima até em baixo, se estivesse com a farda fora do padrão, ele fazia voltar para casa e não entrava na escola de forma alguma... Nunca vou me esquecer daquele olhar. [...] Até mesmo na rua éramos controladas [risos], pelas pessoas que diziam: - 'São moças normalistas'. O regime era pesado.
\end{abstract}

Ainda sobre o uniforme escolar, suas cores, formas e outros aspectos também são evocados na memória da ex-normalista da Escola Normal "Rui Barbosa”, Maria Celina Ferreira da Silva (2013), 76 anos de idade:

A farda era linda [fala saudosa]... Vivíamos com a farda era azul e branco. Aprendíamos a bordar, a desenhar. Tinha desenhos e aprendíamos também a costurar. Tínhamos boas professoras, professoras antigas, professora "Aiazinha Maia". Ela sabia pontos lindos e belíssimos para ensinar a gente.

Pelas narrativas trazidas aqui, podemos perceber que o uso dos uniformes evidencia a ampliação e consolidação de um modelo de controle, mais elaborado e sistemático sobre as alunas do curso normal, pois estas eram logo identificadas como tais, mesmo que na rua. Pois, por trás da graciosidade do uniforme "azul e branco" se escondia uma poderosa arma 
da República, que servia como um freio, pois mesmo fora do colégio, as normalistas carregavam consigo os atributos de uma futura professora da República.

Parafraseando Ribeiro e Souza (2012) o uniforme escolar, no contexto do lugar transitório da rua, passa a ter efeito vigilante, pois se caracteriza por servir como extensão do poder regulador que atua sobre os corpos por meio do uniforme escolar. Uma vez que os alunos que o vestem representam a instituição pelos trajes, dos símbolos, das cores e da organização espacial e física. 0 verbo "controlar", também se fez presente nas Escolas Isoladas do interior, como narra Maria José Bezerra Cerqueira (2013), 82 anos, sobre o uniforme na cidade Riachuelo no ano de 1940:

A escola era pequena, mas tínhamos fardas... Era a saia pinçada na altura do joelho com a blusa branca e a gravatinha [...] os meninos era de calça comprida e camisa estilo marinheiro [risos]. A professora "Elze Dantas" tinha o maior cuidado com nossa farda. Ela olhava também o nosso cabelo, as unhas, os ouvidos... Tudo tinha que estar em ordem, pois ela controlava até isso.

O termo controle, também foi usado por Sônia Souza Maynart (2013), 75 anos, ao falar sobre o uniforme escolar do Grupo Escolar "Padre Dantas", no município de Maruim:

[o uniforme] Era saia e blusa com o escudo do Colégio. No Grupo Escolar tinha um corredor grande e formávamos uma fila para o inspetor olhar o uniforme de um por um. Era um controle como hoje não se vê [...] Tinha inspetor, quando menos se esperava, ele chegava. Era o professor "Sebrão", ele era escritor. Quando ele chegava, a gente se levantava. Ele chegava sem ninguém esperar para olhar nossas fardas e lições.

Assim, como os demais aspectos já abordados, o uniforme escolar faz parte do grande "tronco" da cultura escolar. Pois é um artefato obrigatório que permeia as instituições educativas, por entre cores, combinações e escudos que conferem identidade institucional. As relações e práticas invisíveis e visíveis do disciplinamento corporal, que objetivavam controlar os corpos e homogeneizar o espaço escolar, contou com a presença de um agente que cumpria a função de disciplinar pelo olhar. Olhar vindo dos inspetores, estes considerados "autoridades de ensino" denunciavam com muito afinco a precariedade das condições dos espaços e dos materiais com os quais os professores davam aula.

Talvez isso explique a preocupação dos professores em instruírem os alunos, quanto ao modo de receber os inspetores escolares. Para tanto, recordou saudosamente, Maria Eleotério (2013), a canção que recepcionava cordialmente a visita do inspetor na Escola Isolada em Itaporanga D’Ajuda:

[cantando lentamente] - Recebemos com muita alegria, como uma rosa tão grata visita. Ele veio nos trazer incentivo, animar nossa luta bendita. Legionário da luz contra as trevas; saberemos vitórias colher, essa honra também saberemos da memória jamais esquecer....

Passados mais de dez anos, Marlene Francisca do Carmo Procópio (2012), 69 anos, narrou sobre as inspeções escolares:

[...] 0 inspetor olhava tudo, se a farda estava sendo usada e se já sabíamos ler. Ele sentava e chamava as alunas, ele gostava de ouvir a gente ler. Eu era convidada todas às vezes por ele. Então eu ficava radiante porque na primeira série eu era chamada pra fazer uma leitura pra ele: Ele dizia: - 'Muito bem! Você pontua muito bem, você lê muito bem, tem uma dicção muito boa...' Eu não sabia nem o que era dicção.

Além do inspetor, presença que vigiava e recompensava os alunos, os castigos físicos configuravam outro mecanismo que disciplinava os corpos. As práticas punitivas se fizeram presentes no ambiente escolar do território da Grande Aracaju. Evidência disso, são as revelações feitas por todos os entrevistados, mesmo quem não foi alvejado diretamente pelos castigos, de algum modo, tomaram conhecimentos de tais práticas. Mesmo que a Lei Imperial de 15 de outubro de 1827, entre suas múltiplas determinações, fizesse referência a proibição dos castigos físicos nas escolas, o que se tem registrado, que ainda no fim do século XIX, e início do século XX, os castigos, permaneceu sendo usado nas escolas para disciplinar. 
Tem-se assim, vários itens para punir os alunos que não se enquadrassem no que estava preconizado como ideal. Assim, testemunhou Maria Cecilia Andrade da Silva (2013), 78 anos, sobre a manutenção da ordem pela punição na Escola Isolada na cidade de Santo Amaro das Brotas em 1943:

Eu me lembro muito bem, quando papai foi me levar na escola. Eu fiquei muito tímida e medrosa ao mesmo tempo porque antigamente havia disciplina... Os professores, quando estavam na sala de aula eles tinham que manter aquela ordem e disciplina [...] Quando eu cheguei que olhei para dona "Zumira" [a professora], ela estava com os óculos na ponta do nariz, ela era bem gordona e já era idosa. Eu olhei e vi uma palmatória ${ }^{7}$ em cima da mesa, eu disse: 'Essa professora não é de se brincar!', então eu fui estudar quietinha, sem danação.

As memórias escolares pertencentes à Maria Cecilia evidenciam a presença de disciplinas e ordenamentos impostos pela sua professora primária, "Zumira”, que na detenção do controle sobre os alunos possuía o claro objetivo de manter a ordem. Para melhor entender os mecanismos de disciplinamento instituídos no interior da escola, tomamos emprestadas as palavras de Michel Foucault (1987, p. 126):

A escola exerce sobre o corpo uma coerção sem folga, de mantê-lo ao nível mesmo da mecânica - movimentos, gestos, rapidez, sinais. [...] Esses métodos que permitem o controle minucioso das operações do corpo, são o que podemos chamar as disciplinas.

Assim, a "máquina de ensinar" transforma corpos naturalmente desobedientes em corpos submissos e dóceis, pelo disciplinamento. Tais disciplinamentos têm a função de reduzir os desvios e alinhar comportamentos e gestos considerados desajustados. Por certo, a disciplina dos corpos escolares tende a padronizar os indivíduos, tal coerção foi sentida pela professora, Leopoldina Santos (2013), 85 anos, que ao

\footnotetext{
7 Parafraseando Dalcin (2002) A palmatória se constituía de uma roda de madeira resistente e pesada, de razoável diâmetro, digamos dez centímetros, por uns dois ou três de altura, ou espessura, à qual se ajustava um cabo de aproximadamente vinte centímetros de comprimento, e grossura que permitisse firmeza ao segurar-se o instrumento. Ás vezes era peça inteiriça.
}

escrever com a mão esquerda foi severamente punida pela professora do Grupo Escolar "General Valadão" em Aracaju:

Levei muitos bolos da minha professora porque quando eu comecei a escrever, escrevia com a mão esquerda. Ela [a professora] ficava me observando, até quando ela veio na minha carteira e amarrou a minha mão esquerda, para eu escrever com a direita. Outro dia eu estava no quadro, à professora me deu uma reguada, eu tomei uns toques... Até quando eu mudei a mão e ainda hoje eu escrevo com as duas mãos.

O enquadramento dos corpos também foi sentido pela professora, Maria Antônia Lira dos Santos (2013), 85 anos, na Escola Isolada em Laranjeiras:

Ela [a professora] botava em uma sabatina todo mundo de pé com os braços cruzados, para não estar cutucando, não estar com brincadeira. Ela dizia: - 'Todo mundo com os braços cruzados!'. Disciplina naquele tempo havia [...] Quando ela dizia assim: - 'Amanha eu quero essa casa de tabuada. Você diz toda... se você não souber... - Que já tem uma porção de dias que você está com ela [a tabuada], se você não souber vai ficar de castigo'. Ela deixava em pé estudando a tabuada, às vezes ela balançava assim [balança os braços] crianças mal criadas e respondonas. Para os mais rebeldes, ela usava a palmatória, os pais mandavam usar.

Também narrou o professor Genaro de Almeida Brotas (2013), de 69 anos de idade, sobre o disciplinamento do corpo na Escola Isolada em Laranjeiras:

Todos nós sentávamos perfilados. Não tinha desobediência com a professora, porque sabatina era o terror da escola. Os alunos sabatinados quando erravam, tomavam bolo dos que acertavam. Antes e no decorrer das aulas quase todos nós apanhávamos. Quando a professora dava umas palmadas em um de nós era para exemplar todos da turma... Tinha os dias da sabatina, era segunda, quarta e sexta... eram os dias de terror. Ela [a professora] fazia um pergunta para cada aluno, se não acertasse tomava um bolo.

A presença da palmatória se constituía um símbolo da disciplina rígida empregada nas escolas do território. Pelas memórias escolares dos nossos(as) entrevistados(as) podemos conjecturar que sua utilização cor- 
rigia/inibia os hábitos considerados subversivos, que além de controlar moralmente e fisicamente o aluno castigado, servia de sobreaviso aos outros para que vendo a punição cometida ao colega, não excedessem os limites impostos pelas regras e sobretudo, aprendessem as lições. Além, do controle dos corpos pelos uniformes e punições, outra preocupação era a salvação da alma pela fé no sagrado. Evidência disso, era a presença de elementos e rituais religiosos no interior da escola.

Em linhas gerais nas escolas do território da Grande Aracaju se imperava um discurso católico e os alunos de outras manifestações religiosas tornavam-se invisíveis dentro de uma prática cotidiana escolar que, embora pública, estava pautado no calendário e nos rituais da Igreja Católica. As práticas católicas, como rezar no início da aula como o "Pai Nosso", a "Ave Maria” e o "Santo Anjo", fora ressaltado como prática educativa. Como descreveu Lindaura da Cruz Oliveira (2013), 77 anos, sobre o ensino de Religião dentro da Escola "Doutor José Freire da Costa Pinto", em Nossa Senhora do Socorro:

[...] ela [a professora] ensinava religião, ensina os alunos irem para igreja fazer catequese. Ela era muito religiosa, todos nos aprendemos com ela a religião católica. Ela ensinava ao iniciar a aula que a gente rezasse o Pai Nosso, Ave Maria e tal. [...] Ensinava a gente ir, então a gente ia para igreja e lá fazia a primeira comunhão, se crismava... Todos os sacramentos [...] dia de domingo íamos para a igreja fazer a leitura...

Os preceitos religiosos também podiam/foram incutidos de forma lúdica, por meio da peça "Baile Pastoril”, encenados pelos alunos da professora, Maria José de Carvalho Eleotério (2013) no "Grupo Escolar Felisbelo Freire" em Itaporanga D’Ajuda e na Escola Estadual "Olivia Bittencourt" em Aracaju, nos anos de 1960:

O "Baile Pastoril" era encenado na escola, [narra cantando] 'Muito distante, muito distante ainda estamos em Belém. Apresai, apresai os nossos passos que o dia rompendo vem. Vamos a Belém, vamos sem demora... Vamos a Belém...' Tudo bailando. [retoma cantando] 'Louvar o filho de Nossa Senhora. Nasceu Deus menino em uma manjedoura, nós vamos adorar as delicadas pastoras... Bateu azas, cantou galo quando o salvador nasceu. Cantam os anjos nas alturas gloria hino o sol se deu. Vinte e quatro de dezembro meia noite deu sinal, rompe aurora primavera, foi na noite de Natal... Quando os reis magos souberam que nasceu...' Ai vinha os três Reis Magos, eu dramatizava tudo bonitinho. Um com ouro, incenso e o outro com mirra.

Os ensinamentos religiosos eram incorporados junto ao conjunto de saberes a serem inculcados nos alunos. Muito embora o regime republicano preconizasse a separação do Estado e da Igreja, a prática proselitista da catequização dentro das escolas públicas brasileiras foi um denominador comum à época. Como relevou Maria Eleotério (2013):

Eu quando era aluna aprendi o Catecismo e quando professora, ensinei. O Catecismo perguntava: - "Quem é Deus?” - “Deus é um espírito infinitamente perfeito, criador do céu, da terra e de tudo quando nela existe". - "Onde está Deus?" - "Deus está no céu, na terra e em todos os lugares que se chama por ele".

Conforme a constituição de 1891 e depois dos ideais da Escola Nova ${ }^{8}$, sobretudo a partir de 1930, o ensino religioso só poderia/deveria ser ministrado apenas em alguns estabelecimentos específicos, como por exemplo, nas escolas de cunho religioso confessional e não mais naquelas mantidas pelo Poder Público. Contudo à revelia da lei houve a manutenção dos feriados religiosos que contrapunham aos princípios republicamos da escola laica. Assim, a descontinuidade entre o dito e o prescrito é claramente evidenciada pelas narrativas de quem viveu no interior da escola.

\section{APAGANDO AS LUZES - "FIM..."}

O tempo passou, mas ficaram na memória as lembranças da minha escola. O tempo que passávamos lá, os recreios, os uniformes, as provas, até mesmo a palmatória nos dias de sabatina. Tempo que não volta mais...

Maria Sinesia Oliveira Belém (2013).

As palavras emprestadas de Maria Sinesia Oliveira Belém indicam um pouco do que queríamos: encontrar

8 No manifesto dos Pioneiros da Educação Nova, a laicidade tem como objetivo desatrelar a escola de qualquer credo religioso. 
os ritos e rotinas na temporalidade escolar. Concordamos com as palavras da nossa entrevistada, quando asseverou que: "O tempo não volta mais". Pois para evidenciamos as narrativas, que trouxeram consigo imagens, cenas e capítulos da História da Educação sergipana pensamos o passado como uma invenção, composto por parte sucessivas de discursos e práticas. Percebemos que o passado narrado por nossos(as) entrevistados(as) é uma representação do vivido, que não se apresentou para nós de forma linear e tranquila.

Damo-nos conta, nos desdobramos desta pesquisa, de que a História não está somente a serviço da memória, de sua redenção, mas está, sim, também a serviço do quase esquecido, do quase negado, do quase apagado. Ela está sempre passível de ser reeditada, pois uma imagem do passado que já tinha sido construída, petrificada, engessada, pode, a partir de novos referenciais, ganhar outras versões e sentidos. Foi nesse movimento que seguimos evidências deixadas pelas narrativas dos(as) professoras(as) que nos revelaram uma história que distante do que definiam os preceitos e normativos oficiais, é a representação de como os atores do cotidiano escolar se movimentaram e interagiram na produção deste cotidiano.

Cotidiano este, marcado por um tempo em que a consolidação do ensino primário se torna primordial no país e está atrelado aos princípios republicanos. De tal maneira a demarcação do início, duração e término dessas atividades se davam por meio das férias, exames, recreios e comemorações patrióticas, bem como do detalhamento e desdobramento do trabalho pedagógico. Desse modo, dias, semanas, meses e anos conformou um "grande relógio" que cuidou por entregar sentido e lógica o tempo escolar.

Não obstante a estes propósitos o controle dos corpos pelos uniformes escolares traduzia a intenção de uniformizar e homogeneizar os alunos. Assim, o uso dos uniformes nas dependências da escola e, de maneira mais ampla nas ruas, representava o pertencimento a uma instituição educativa, tal prerrogativa alargava ainda mais o controle sobre os corpos. Tal controle também era exercido pelo uso de castigos físicos e práticas religiosas, que por certo, todos re- presentavam um conjunto de medidas que vigiavam e puniam os corpos dos alunos.

Ao partir da premissa de que só podemos historicizar aquilo que o homem deixou rastros, em dado momento e espaço. Desse modo, com a retenção e sistematização dessas informações oferecemos e propomos aos demais pesquisadores a soma de experiências existentes com pesquisas que se valem da teoria da História Cultural, bem como da metodologia da História Oral.

Assim, o que queremos é alargar possibilidades e abrir caminhos na produção do conhecimento em História da Educação de Sergipe. Para tanto, mergulhamos nas evidencias deixadas pelas memórias dos professores(as) e agora concluímos que tais ritos e rotinas é consolidação de práticas que se estabeleceram de forma compartilhada no interior da escola. Assim, nossa hipótese foi confirmada, pois a temporalidade escolar foi fundada por intermédio de tais práticas, que por sua vez, é a soma das determinações institucionais e a atuação de sujeitos que vivenciaram e também instituíram ritos e rotinas na escola.

\section{REFERÊNCIAS}

ALBERTI, Verena. Manual de história oral. Rio de Janeiro: FGV, 2004.

ANDRADE, Etemízia Ramos Batista. Relato oral sobre sua história de vida. Entrevista concedida a Rony rei do Nascimento Silva. São Cristóvão, 22 fev. 2013.

\section{ANDRADE, Maria Aliete Marinho. Relato oral sobre}

sua história de vida. Entrevista concedida a Rony Rei do Nascimento Silva. Riachuelo, 26 fev. 2013.

ÁVILA, Virgínia Pereira da Silva de. Sobre relógios e tempo escolar: ritos, rituais e rotinas. In: SILVA, Vera Lucia Gaspar; PETRY Marilia Gabriela (Org.).

Objetos da Escola: espaços e lugares de construção da cultura material escolar (Santa Catarina - séculos XIX e XX). Florianópolis: Insular, 2012. 
BELÉM, Maria Sinesia Oliveira. Relato oral sobre sua história de vida. Entrevista concedida a Rony Rei do Nascimento Silva. Aracaju, 6 mar. 2013.

BROTAS, Genaro de Almeida. Relato oral sobre sua história de vida. Entrevista concedida a Rony Rei do Nascimento Silva. Laranjeiras, 22 fev. 2013.

CERQUEIRA, Maria José Bezerra. Relato oral sobre sua história de vida. Entrevista concedida a Rony Rei do Nascimento Silva. Riachuelo, 19 fev. 2013.

CHARTIER, Roger. A História Cultural: entre práticas e representações. Rio de Janeiro: Bertrand Brasil,1990.

DALCIN, Talita B. Os castigos corporais nas escolas domésticas e isoladas do Paraná no século XIX: disciplina e controle dos corpos. UFPR - CAPES. 2005. Disponível em: <http://dspace.c3sl.ufpr.br>. Acesso em: 5 jul. 2013.

FOUCAULT, Michel. Vigiar e punir. História da violência nas prisões. 15.ed. Trad. Raquel Ramalhete. Petrópolis: Vozes, 1987.

ELEOTÉRIO, Maria José de Carvalho. Relato oral sobre sua história de vida. Entrevista concedida a Rony rei do Nascimento Silva. Itaporanga D’Ajuda, 14 jan. 2013.

GASPAR DA SILVA, Vera Lucia. Vitrines da República: Os grupos Escolares em Santa Catarina (1889-1930). In: VIDAL, Diana Gonsalves (Org.). Grupos escolares: cultura escolar primária e escolarização da infância no Brasil (1893-1971). Campinas, São Paulo: Mercado das Letras, 2006. p.341-376.

JULIA, D. A cultura escolar como objeto histórico.

Revista Brasileira de História da Educação, Campinas, n.1, p.9-44, 2001.
MAYNART, Sônia Souza. Relato oral sobre sua

história de vida. Entrevista concedida a Rony Rei do Nascimento Silva. Maruim, 19 fev. 2013.

OLIVEIRA, Lindaura da Cruz. Relato oral sobre sua história de vida. Entrevista concedida a Rony Rei do Nascimento Silva. Nossa Senhora do Socorro, 8 mar. 2013.

OLIVEIRA, Maria José da Conceição de. Relato oral sobre sua história de vida. Entrevista concedida a Rony Rei do Nascimento Silva. Barra dos Coqueiros, 27 fev. 2013.

PINA, Maria Ligia Madureira. Relato oral sobre sua história de vida. Aracaju. Entrevista concedida a Rony Rei do Nascimento Silva, Raylane Andreza Dias Navarro Barreto e Laisa Dias Santos, 20 abr. 2011.

PROCÓPIO, Marlene Francisca do Carmo. Relato oral sobre sua história de vida. Entrevista concedida a Rony Rei do Nascimento Silva. Aracaju, 29 ago. 2012.

RIBEIRO, Ivanir; SOUZA, Luani de Liz. Corpos escolares, leitura e imagens: o uniforme escolar na Escola Técnica Federal de Santa Catarina - 1964 a 1985. In: SILVA, Vera Lucia Gaspar; PETRY Marilia Gabriela (Org.). Objetos da escola: espaços e lugares de construção da cultura material escolar (Santa Catarina - séculos XIX e XX). Florianópolis: Insular, 2012.

\section{SANTOS, Leopoldina. Relato oral sobre sua história} de vida. Entrevista concedida a Rony Rei do Nascimento Silva. Itaporanga D’Ajuda, 15 jan. 2013.

SANTOS, Lurdes Tavares dos. Relato oral sobre sua história de vida. Entrevista concedida a Rony Rei do Nascimento Silva. São Cristóvão, 15 jan. 2013.

SANTOS, Maria Antônia Lira dos. Relato oral sobre sua história de vida. Entrevista concedida a Rony Rei do Nascimento Silva. Laranjeiras, 1 mar. 2013. 
SANTOS, Maria Valdomira de Carvalho. Relato oral sobre sua história de vida. Entrevista concedida a Rony Rei do Nascimento Silva. São Cristóvão, 20 fev. 2013.

SILVA, Geraldo Bastos. A educação secundária: perspectiva histórica e teórica. São Paulo: Nacional, 1969.
SILVA, Maria Cecilia Andrade da. Relato oral sobre sua história de vida. Entrevista concedida a Rony Rei do Nascimento Silva. Santo Amaro das Brotas, 10 abr. 2013.

SILVA, Maria Celina Ferreira da. Relato oral sobre sua história de vida. Entrevista concedida a Rony Rei do Nascimento Silva. Barra dos Coqueiros, 26 fev. 2013.

VIDAL, D.G.; FARIA FILHO, L. Os tempos e os espaços escolares no processo de institucionalização da escola primária no Brasil. Revista Brasileira de Educação, Rio de Janeiro, n.14, p.19-34, 2000. 
